\title{
Glycemic Control in Coronary Artery Bypass Graft Surgery: A Different Perspective
}

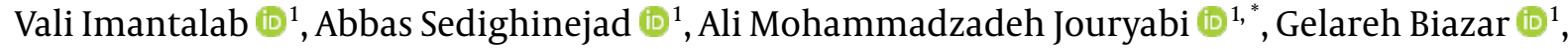 \\ Gholamreza Kanani (iD ${ }^{2}$, Mohammad Haghighi (iD) ${ }^{1}$, Haniyeh Sadat Fayazi (iD) ${ }^{3}$ and Golnoosh \\ Ghasvareh $^{4}$ \\ ${ }^{1}$ Anesthesiology Research Center, Department of Anesthesiology, Alzahra Hospital, Guilan University of Medical Sciences, Rasht, Iran \\ ${ }^{2}$ Department of Cardiology, School of Medicine, Guilan University of Medical Sciences, Rasht, Iran \\ ${ }^{3}$ Razi Clinical Reseach Development Unit, Guilan University of Medical Sciences, Rasht, Iran \\ ${ }^{4}$ Student Research Committee, School of Medicine, Guilan University of Medical Sciences, Rasht, Iran \\ "Corresponding author: Anesthesiology Research Center, Department of Anesthesiology, Alzahra Hospital, Guilan University of Medical Sciences, Rasht, Iran. Email: \\ alimohammadzadehanesthesiology@gmail.com
}

Received 2021 October 10; Revised 2021 November 30; Accepted 2021 December 07.

\begin{abstract}
Background: Hyperglycemia during coronary artery bypass graft surgery (CABG) strongly predicts intra- and post-operative adverse consequences.

Objectives: This study aimed to evaluate the quality of glycemic management during CABG in an academic center regarding peripheral blood and coronary sinus values.

Methods: This prospective descriptive study encompassed 55 eligible patients undergoing on-pump CABG surgery in 2020. Peripheral blood glucose (BG) was measured four times, before anesthesia induction (T0), before cardiopulmonary bypass pump (CPB) (T1), during $\mathrm{CPB}$ (T2), at the end of $\mathrm{CPB}$ (T3), and at the end of surgery (T4). The surgeon also took a sample of the coronary sinus BG. Results: The BG variations from To to T4 were statistically significant $(\mathrm{P}<0.0001)$. The higher values detected in the ASA class III compared to ASA classes II were statistically significant at $\mathrm{T} 1(\mathrm{P}=0.01)$ and $\mathrm{T} 2(\mathrm{P}=0.025)$ : patients with the higher BMI showed the higher levels of $\mathrm{BG}$. In this regard, the differences were significant at T0 $(\mathrm{P}=0.0001), \mathrm{T} 2(\mathrm{P}=0.004)$, and T3 $(\mathrm{P}=0.015)$. Regarding coronary sinus, the mean BG was $222.18 \pm 75.74 \mathrm{mg} / \mathrm{dL}$. It was also observed that the ASA class III $(\mathrm{P}=0.001)$, longer duration of $\mathrm{CPB}$ $(\mathrm{P}=0.021)$, higher IV fluid volume administrated during surgery $(\mathrm{P}=0.023)$, higher $\mathrm{BMI}(\mathrm{P}=0.0001)$, and less urine volume at the end of surgery $(\mathrm{P}=0.049)$ were significantly associated with the higher $\mathrm{BG}$ of the coronary sinus.

Conclusions: The existing glycemic management protocols on the CABG patients were acceptable in our hospital. However, the BG level of the coronary sinus was higher than the peripheral one.
\end{abstract}

Keywords: Blood Glucose, Coronary Artery Bypass Surgery, Coronary Sinus

\section{Background}

Nowadays, the incidence of CABG as a lifesaving intervention has been increasing worldwide $(1,2)$; however, there may be some intra and post-operative complications $(3,4)$. BG control during CABG is one of the main tasks of anesthesiologists (5). Higher fasting BG levels with intra-operative fluctuations are strong predictors of intraand post-operative complications such as morbidity and mortality, neurologic damage, cardiac injury, surgical site infection, and longer hospital stay in diabetic and nondiabetic patients $(6,7)$. When BG values rise, hemoglobin molecules become glycosylated via a non-enzymatic reaction. This harmful process leads to the free radical for- mation (8). In this process, the administration of anesthesia drugs and insulin with proper dosage and timing, well-controlled diabetes other co-morbidities, СРB duration, and the use of inotropic agents and interventions to eliminate stress response to surgery stimulants are some of the effective factors (9-11).

\section{Objectives}

This study aimed to assess the quality of glycemic control in diabetic patients undergoing on-pump CABG surgery in an academic center in the north of Iran. 


\section{Methods}

This prospective-descriptive study was performed at the Dr. Heshmat Hospital, an academic center affiliated with the Guilan University of Medical Science (GUMS), in 2020.

\subsection{Inclusion Criteria}

Diabetic patients undergoing isolated CABG surgery, aged 35 - 80 years and ASA class II \& III.

\subsection{Exclusion Criteria}

Severe or unexpected complications changing the methods of anesthesia or surgery, patient not willing to submit their informed consent.

Arriving at the operating room, the patients underwent standard monitoring, and general anesthesia and surgery protocols were considered for these patients. BG was measured four times, before the induction of anesthesia (T0), before CPB (T1), during CPB (T2), at the end of CPB (T3), and at the end of surgery (T4). During the surgery, the surgeon took a sample from the coronary sinus and measured BG. Additionally, information addressing gender, age, BMI, ASA class, EF percentage, duration of surgery, duration of the $\mathrm{CPB}$, the volume of administrated IV fluids during surgery, and urine volume at the end of surgery was also recorded. The target was to maintain $\mathrm{BG}$ in the range of $80-180 \mathrm{mg} / \mathrm{dL}$. When BG $>200 \mathrm{mg} / \mathrm{dL}$, a bolus of 4 units of insulin regular was administrated. For BG $<80 \mathrm{mg} / \mathrm{dL}$, $50 \mathrm{~mL} / \mathrm{h}$ of dextrose $5 \%$ was administered. BG was measured hourly using a touch glucometer, and the dosage was repeated until the reached values were $<200 \mathrm{mg} / \mathrm{dL}$.

\subsection{Statistical Analysis}

The data were analyzed with SPSS software version 21 . Chi-square, $t$-test, repeated measurement test, and ANOVA analysis were also used for the data analyses. Statistically, a $\mathrm{P}<0.05$ was set as the significance level.

\section{Results}

Fifty-five patients (34 (61.8\%) men and 21 (38.2\%) women) meeting the inclusion criteria took part in the survey. The participants' mean age was $57.54 \pm 9.29$ years, $65.5 \%$ and $34.5 \%$ of whom were the ASA class II and the ASA class III. The mean years of diabetes was $10.6 \pm 3.89$, the mean duration of surgery was $181.09 \pm 45.13$ minutes, the mean urine volume was $1292.36 \pm 505.8 \mathrm{~mL}$, and the mean administrated IV fluids was $2268.2 \pm 512.2$ milliliters.
Table 1 shows the patient's demographic information and surgery characteristics. The mean BG was $222.18 \pm 75.74$ $\mathrm{mg} / \mathrm{dL}$, and the trend of BG variations from To to T4 was significant $(\mathrm{P}<0.0001)$ (Table 2$)$.

\begin{tabular}{|c|c|}
\hline Variables & Values \\
\hline \multicolumn{2}{|l|}{ Gender } \\
\hline Male & $34(61.8)$ \\
\hline Female & $21(38.2)$ \\
\hline Age (y) & $57.54 \pm 9.29$ \\
\hline$\leq 60$ & $35(63.6)$ \\
\hline$>60$ & $20(36.4)$ \\
\hline $\operatorname{BMI}\left(\mathbf{k g} / \mathbf{m}^{2}\right)$ & $26.52 \pm 3.24$ \\
\hline Normal (less than 25) & $19(34.5)$ \\
\hline Overweight (30 - 25) & $27(49.1)$ \\
\hline Obese (more than 30) & $9(16.4)$ \\
\hline \multicolumn{2}{|l|}{ ASA class } \\
\hline II & $36(65.5)$ \\
\hline III & $19(34.5)$ \\
\hline $\mathbf{E F}(\%)$ & $41.63 \pm 10.45$ \\
\hline$\leq 40$ & $27(49.1)$ \\
\hline$>40$ & $28(50.9)$ \\
\hline Blood sugar (mg/dL) & $123.1 \pm 29.91$ \\
\hline Duration of surgery (min) & $181.09 \pm 45.13$ \\
\hline Duration of cardiopulmonary pump (min) & $68.69 \pm 21.8$ \\
\hline Fluid volume received during surgery $(\mathrm{mL})$ & $2268.2 \pm 512.2$ \\
\hline Urine volume at the end of surgery $(\mathrm{mL})$ & $1292.36 \pm 505.8$ \\
\hline
\end{tabular}

In this study, the recorded values did not differ significantly in terms of gender $(\mathrm{P}=0.873)$, age $(\mathrm{P}=0.99)$, $\mathrm{BMI}(\mathrm{P}$ $=0.177), \mathrm{CPB}$ time $(\mathrm{P}=0.706), \mathrm{EF} \%(\mathrm{P}=0.197)$, the amount of fluids received during surgery $(\mathrm{PP}=0.079)$, and ASA classes $(\mathrm{P}=0.269)$. Although higher levels were observed in older women, the pump period lasted $>60$ minutes. Furthermore, the higher values were noticed in the ASA class III compared to ASA classes II, indicating statistically significant differences at $\mathrm{T} 1(\mathrm{P}=0.01)$ and $\mathrm{T} 2(\mathrm{P}=0.025)$. Moreover, patients with higher BMI showed higher BG levels, suggesting significant differences at To $(\mathrm{P}=0.0001), \mathrm{T} 2(\mathrm{P}=0.004)$, and T3 $(\mathrm{P}=0.015)$. Patients with urine $<1000 \mathrm{cc}$ at the end of surgery had significantly higher BG levels at $\mathrm{T} 1(\mathrm{P}=0.03)$, T2 $(\mathrm{P}=0.006)$, and $\mathrm{T} 3(\mathrm{P}=0.01)$. When they received intravenous fluids $>2000$ cc during surgery, it was significant at T2 $(\mathrm{P}=0.043)$ (Table 3$)$. 


\begin{tabular}{|c|c|c|c|c|c|c|c|c|}
\hline \multirow{2}{*}{ Title } & \multicolumn{6}{|c|}{ Period } & \multirow{2}{*}{\multicolumn{2}{|c|}{ P-Value }} \\
\hline & Before Induction & Before CPB & During Pump & \multicolumn{2}{|c|}{ After the End of CPB } & $\begin{array}{c}\text { After the End of } \\
\text { Surgery }\end{array}$ & & \\
\hline $\begin{array}{l}\text { Blood sugar levels } \\
(\mathrm{mg} / \mathrm{dL})\end{array}$ & $124.07 \pm 29.46$ & $148.12 \pm 36.3$ & $175.61 \pm 55.34$ & \multicolumn{2}{|c|}{$184.8 \pm 60.69$} & $168.07 \pm 50.49$ & \multicolumn{2}{|c|}{$\mathrm{F}=32.76, \mathrm{P}=0.0001$} \\
\hline Variables & Status & $\begin{array}{c}\text { Before } \\
\text { Induction } \\
\quad(\mathrm{T} 0)\end{array}$ & $\begin{array}{l}\text { Before CPB } \\
\quad \text { (T1) }\end{array}$ & $\begin{array}{c}\text { During } \\
\text { Pump,(T2) }\end{array}$ & $\begin{array}{l}\text { After the } \\
\text { End of CPB } \\
\text { (T3) }\end{array}$ & $\begin{array}{l}\text { After the } \\
\text { End of } \\
\text { Surgery } \\
\text { (T4) }\end{array}$ & $\begin{array}{l}\text { Intragroup } \\
\text { Statistical } \\
\text { Estima- } \\
\text { tion }\end{array}$ & $\begin{array}{c}\text { Intergroup } \\
\text { Statistical } \\
\text { Estima- } \\
\text { tion, }\end{array}$ \\
\hline \multirow{2}{*}{ Gender } & Male & \multirow{2}{*}{$\begin{array}{c}t=1.41, \mathrm{P}= \\
0.164\end{array}$} & \multirow{2}{*}{$\begin{aligned} t= & 0.85, \mathrm{P}= \\
& 0.397\end{aligned}$} & \multirow{2}{*}{$\begin{aligned} t= & 0.211, \mathrm{P}= \\
& 0.834\end{aligned}$} & \multirow{2}{*}{$\begin{aligned} t & =0.044, \mathrm{P} \\
& =0.965\end{aligned}$} & \multirow{2}{*}{$\begin{aligned} t= & 0.55, \mathrm{P}= \\
& 0.581\end{aligned}$} & $P=0.0001$ & \multirow{2}{*}{$\begin{aligned} \mathrm{F}= & 0.24, \mathrm{P}= \\
& 0.873\end{aligned}$} \\
\hline & Female & & & & & & $P=0.0001$ & \\
\hline \multirow{2}{*}{ Age } & $\leq 60$ & \multirow{2}{*}{$\begin{aligned} t & =0.786, P \\
& =0.434\end{aligned}$} & \multirow{2}{*}{$\begin{array}{c}t=0.43, \mathrm{P}= \\
0.669\end{array}$} & \multirow{2}{*}{$t=0.58, \mathrm{P}=$} & \multirow{2}{*}{$\begin{aligned} t & =0.402, \mathrm{P} \\
& =0.689\end{aligned}$} & \multirow{2}{*}{$\begin{aligned} t & =0.565, \mathrm{P} \\
& =0.574\end{aligned}$} & $\mathrm{P}=0.0001$ & \multirow{2}{*}{$\begin{aligned} \mathrm{F}= & 0.04, \mathrm{P}= \\
& 0.99\end{aligned}$} \\
\hline & $>60$ & & & & & & $P=0.0001$ & \\
\hline \multirow{3}{*}{ BMI } & $\begin{array}{c}\text { Normal } \\
\text { (less than } \\
25)\end{array}$ & \multirow{3}{*}{$\begin{array}{c}t=11.44, \mathrm{P}= \\
0.0001\end{array}$} & \multirow{3}{*}{$\begin{array}{c}t=3.07, \mathrm{P}= \\
0.054\end{array}$} & \multirow{3}{*}{$\begin{array}{c}t=6.1, \mathrm{P}= \\
0.004\end{array}$} & & & $P=0.0001$ & \\
\hline & $\begin{array}{c}\text { Overweight } \\
(25-30)\end{array}$ & & & & $\begin{aligned} t= & 4.52, \mathrm{P}= \\
& 0.015\end{aligned}$ & $\begin{aligned} t= & 2.34, \mathrm{P}= \\
& 0.106\end{aligned}$ & $P=0.0001$ & $\begin{array}{c}\mathrm{F}=1.51, \mathrm{P}= \\
\quad 0.177\end{array}$ \\
\hline & $\begin{array}{c}\text { Obese } \\
\text { (more than } \\
30)\end{array}$ & & & & & & $P=0.0001$ & \\
\hline ASA class & II & $t=0.88, \mathrm{P}=$ & $t=2.59, \mathrm{P}=$ & $t=2.31, \mathrm{P}=$ & $t=1.09, \mathrm{P}=$ & $t=1.2, \mathrm{P}=$ & $\mathrm{P}=0.0001$ & $\mathrm{~F}=1.32, \mathrm{P}=$ \\
\hline & III & 0.383 & 0.012 & 0.025 & 0.279 & 0.234 & $P=0.0001$ & 0.269 \\
\hline EF & $\leq 40 \%$ & $t=1.51, \mathrm{P}=$ & $t=1.74, \mathrm{P}=$ & $t=1.27, \mathrm{P}=$ & $t=0.382, \mathrm{P}$ & $t=0.547, \mathrm{P}$ & $\mathrm{P}=0.0001$ & $\mathrm{~F}=1.57, \mathrm{P}=$ \\
\hline & $>40 \%$ & 0.135 & 0.087 & 0.207 & $=0.704$ & $=0.587$ & $P=0.0001$ & 0.198 \\
\hline Duration of surgery & $\leq 180 \mathrm{~min}$ & $t=1.39, \mathrm{P}=$ & $t=0.44, \mathrm{P}=$ & $t=0.971, \mathrm{P}=$ & $t=0.006, \mathrm{P}$ & $t=0.195, \mathrm{P}=$ & $\mathrm{P}=0.0001$ & $\mathrm{~F}=1.24, \mathrm{P}=$ \\
\hline & $>180 \mathrm{~min}$ & 0.17 & 0.661 & 0.336 & $=0.995$ & 0.846 & $P=0.0001$ & 0.296 \\
\hline Duration of the & $\leq 60 \mathrm{~min}$ & $t=0.071, \mathrm{P}=$ & $t=1.15, \mathrm{P}=$ & $t=0.759, \mathrm{P}$ & $t=0.352, \mathrm{P}=$ & $t=1.01, \mathrm{P}=$ & $P=0.0001$ & $\mathrm{~F}=0.471, \mathrm{P}=$ \\
\hline cardiopulmonary pump & $>60 \mathrm{~min}$ & 0.944 & 0.252 & $=0.452$ & 0.746 & 0.313 & $P=0.0001$ & 0.706 \\
\hline Fluid volume received during & $\leq 2000 \mathrm{~mL}$ & $t=0.345, \mathrm{P}$ & $t=0.811, \mathrm{P}=$ & $t=2.07, \mathrm{P}=$ & $t=1.14, \mathrm{P}=$ & $T=0.424, \mathrm{P}$ & $\mathrm{P}=0.0001$ & $\mathrm{~F}=2.29, \mathrm{P}=$ \\
\hline surgery & $>2000 \mathrm{~mL}$ & $=0.732$ & 0.421 & 0.043 & 0.2560 & $=0.673$ & $\mathrm{P}=0.0001$ & 0.079 \\
\hline Urine volume at the end of & $\leq 1000 \mathrm{~mL}$ & $t=0.907, \mathrm{P}$ & $t=2.17, \mathrm{P}=$ & $t=2.87, \mathrm{P}=$ & $t=2.58, \mathrm{P}=$ & $t=1.88, \mathrm{P}=$ & $\mathrm{P}=0.0001$ & $\mathrm{~F}=2.83, \mathrm{P}=$ \\
\hline surgery & $>1000 \mathrm{~mL}$ & $=0.368$ & 0.034 & 0.006 & 0.013 & 0.065 & $\mathrm{P}=0.0001$ & 0.038 \\
\hline
\end{tabular}

Furthermore, ASA class III $(\mathrm{P}=0.001)$, longer duration of $\mathrm{CPB}(\mathrm{P}=0.021)$, higher IV fluid volume administrated during surgery $(\mathrm{P}=0.023)$, higher $\mathrm{BMI}(\mathrm{P}=0.0001)$, and less urine volume at the end of surgery $(\mathrm{P}=0.049)$ were significantly associated with higher $\mathrm{BG}$ values of the coronary sinus. However, there was no statistically significant difference between the mean coronary sinus BG levels with gen$\operatorname{der}(\mathrm{P}=0.453)$, age $(\mathrm{P}=0.516), \mathrm{EF} \%(\mathrm{P}=0.363)$, and duration of surgery $(\mathrm{P}=0.501)$ (Table 4$)$.

\section{Discussion}

This study revealed that the current protocols on the BG management in CABG patients provided a proper intra-operative glycemic control. The increasing trend of changes in BG values from To to T4, peaked in T3, was statistically significant. This finding supported the finding of a previous study suggesting the association between the severity of stress response during CABG surgery and BG values (12).

Although the mean BG concentrations were $<200$ $\mathrm{mg} / \mathrm{dL}$, the mean $\mathrm{BG}$ values of the coronary sinus were 


\begin{tabular}{|c|c|c|c|}
\hline Variables & Number & Mean \pm SD & P-Value \\
\hline Gender & & & 0.453 \\
\hline Male & 30 & $215.87 \pm 1.28$ & \\
\hline Female & 25 & $230.73 \pm 68.23$ & \\
\hline Age $(y)$ & & & 0.516 \\
\hline$\leq 60$ & 33 & $216.69 \pm 73.79$ & \\
\hline$>60$ & 22 & $230.79 \pm 4.58$ & \\
\hline BMI & & & 0.0001 \\
\hline Normal (less than 25) & 19 & $187 \pm 64.73$ & \\
\hline Overweight (25-30) & 27 & $222.85 \pm 62.59$ & \\
\hline Obese (more than 30 ) & 9 & $294.44 \pm 88$ & \\
\hline ASA class & & & 0.001 \\
\hline II & 36 & $198.69 \pm 61.98$ & \\
\hline III & 19 & $266.66 \pm 84.84$ & \\
\hline $\mathbf{E F}(\%)$ & & & 0.363 \\
\hline$\leq 40$ & 27 & $212.79 \pm 62.64$ & \\
\hline$>40$ & 28 & $213.39 \pm 72.01$ & \\
\hline Duration of surgery & & & 0.501 \\
\hline$\leq 180 \mathrm{~min}$ & 32 & $216.73 \pm 28.46$ & \\
\hline$>180 \mathrm{~min}$ & 23 & $230.79 \pm 39.71$ & \\
\hline Duration of cardiopulmonary pump & & & 0.021 \\
\hline$\leq 60 \min$ & 20 & $191.72 \pm 25.09$ & \\
\hline$>60 \mathrm{~min}$ & 35 & $239.72 \pm 85.95$ & \\
\hline Fluid volume received during surgery & & & 0.023 \\
\hline$\leq 2000 \mathrm{~mL}$ & 28 & $199.74 \pm 64.86$ & \\
\hline$>2000 \mathrm{~mL}$ & 27 & $245.70 \pm 55.57$ & \\
\hline Urine volume at the end of surgery & & & 0.049 \\
\hline$\leq 1000 \mathrm{~mL}$ & 17 & $252.05 \pm 81.2$ & \\
\hline$>1000 \mathrm{~mL}$ & 38 & $208.70 \pm 81.19$ & \\
\hline
\end{tabular}

$222.18 \pm 75.74 \mathrm{mg} / \mathrm{dL}$, which was higher than the peripheral sample values at the same measurement time point. The coronary sinus, the largest coronary vein, is formed by converging several vessels. It collects blood from the myocardium and drains deoxygenated blood directly into the right atrium $(13,14)$. During $C A B G$, the anatomic feature of the coronary sinus plays a critical role as a landmark for the surgeon and an effective place to transmit cardioplegia solution to protect the myocardium (15).

As it was mentioned, the BG levels of the coronary sinus were different from peripheral samples. The exact underlying mechanism of this positive difference has not been well-understood; however, it could be due to hypothermia and cardiologic solutions containing glucose, which led to lower myocardial glucose uptake (Figure 1). Given the specific and critical function of the coronary sinus, directly representing myocardial metabolism, it is theoretically hypothesized that peripheral BG measurement alone could not be a reliable finding. However, the main goal of preoperative glycemic control would be to improve clin- ical outcomes. Accordingly, further studies are required to achieve practical findings and clarify the effect of coronary sinus BG on short- and long-term outcomes. It is unknown whether the intervention is necessary to correct coronary sinus BG despite proper peripheral glycemic control. A fundamental study showed that coronary sinus BG did not match peripheral sampling; hence, future studies should shed light on several unanswered questions. Previous studies have demonstrated that myocardial glucose increases due to higher coronary sinus blood flow during the increased heart work. Similar studies have indicated that when the human heart is at rest, only $20-25 \%$ of the myocardial glucose uptake is oxidized (16).

Gertz et al. found that during rest, myocardial energy needs are mainly provided by fat; hence, the BG concentrations increase. In contrast, during the heart's function, the myocardial section mainly tends to consume glucose (17). Bergman et al. examined the myocardial glucose metabolism by measuring coronary sinus BG during pacing. They found that coronary sinus glucose con- 


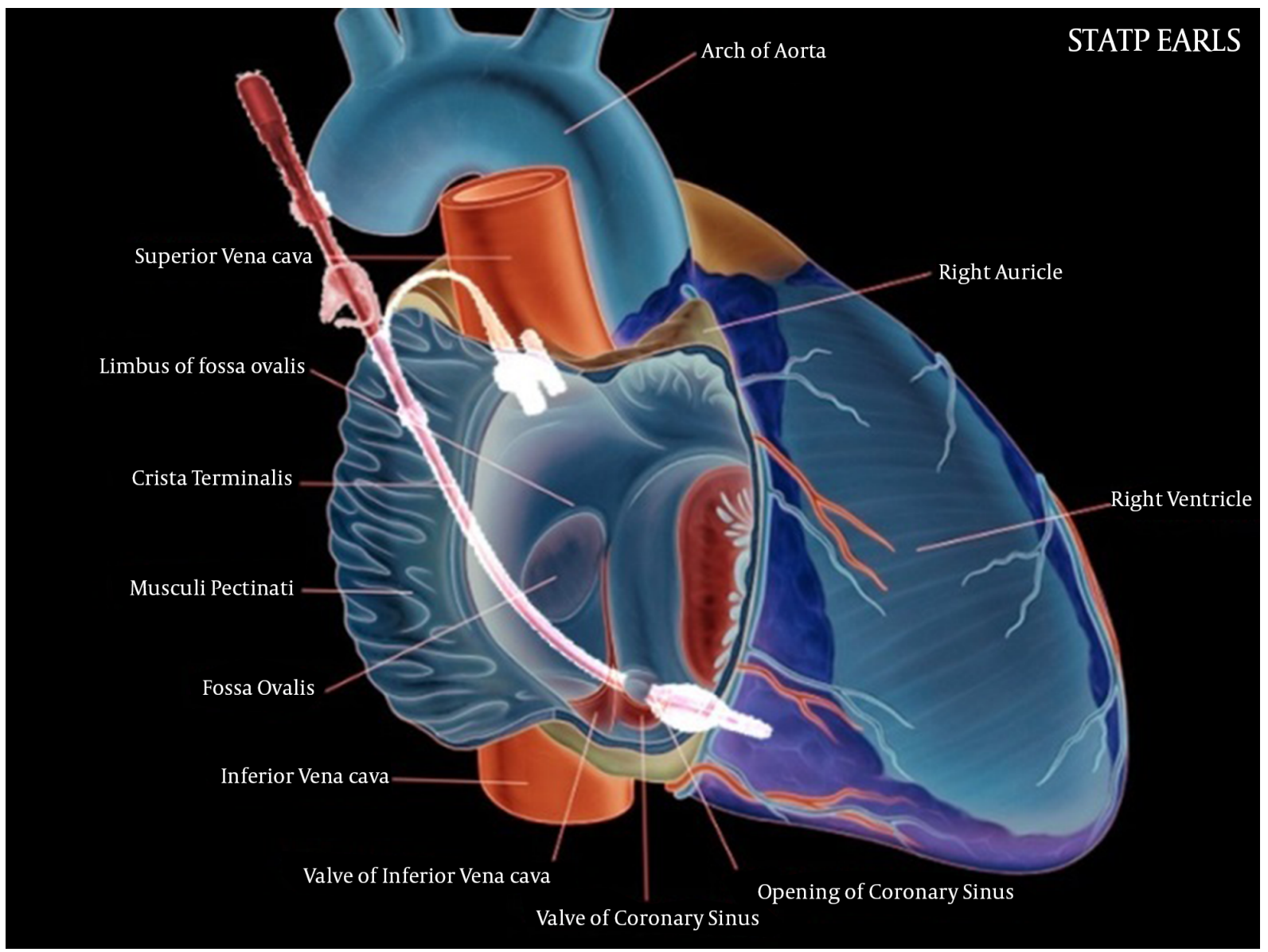

Figure 1. Anatomical location of coronary sinus for blood sampling

centration was significantly lower than arterial samples. Their justification was that during most of the heart's functions, higher glucose was delivered via high coronary sinus blood flow (18). Sathya et al. detected that moderate glycemic control targeting $(150-200 \mathrm{mg} / \mathrm{dL}$ ) led to postoperative mortality and stroke reduction compared to a liberal strategy ( $>200 \mathrm{mg} / \mathrm{dL}$ ). However, there was no definite addition with more intensity ( $<150 \mathrm{mg} / \mathrm{dL}$ ) (19).

According to the existing protocols, the BG levels should be kept $<180 \mathrm{mg} / \mathrm{dL}$, and strict control on BG $<110$ $\mathrm{mg} / \mathrm{dL}$ is no longer recommended (6).

In general, some studies have suggested the increased mortality rate in the CABG patients undergoing strict glycemic control protocols (20). The acceptable results of this study indicate that anesthesiologists in this hospital have a close and continuous communication with the surgeon during the critical surgery stages. A detailed physical examination is performed in preoperative visits, and medical history, including patients' medications and comorbidities, is obtained.

\subsection{Conclusions}

These findings indicated that coronary sinus BG was higher than peripheral values. Despite the optimal control of BG based on peripheral sampling, the significance and clinical values of coronary sinus BG should be investigated. Moreover, the existing protocol in the concerned hospital was found to be acceptable. Special attention should be paid to older patients with higher ASA classes.

\section{Footnotes}

Authors' Contribution: Conception and design: V.I; Data collection: A. M. J., G. Gh. \& Gh. K. Analysis and interpretation: H.F.; Drafting of the article: G. B. \& M. H.; Critical revision of the article for important intellectual content: A. S.; Final approval of the article: A. S. 
Conflict of Interests: The authors have no conflicts of interest to report.

Ethical Approval: Ethical approval was received from the Ethics Committee of the Guilan University of Medical Science (Code: IR.GUMS.REC.1398.516).

Funding/Support: No funding was used in this study.

Informed Consent: Participants were included in the study after obtaining their written informed consent.

\section{References}

1. Hadipourzadeh F, Mousavi S, Heydarpur A, Sadeghi A, Ferasat-Kish R. Evaluation of the Adding Paracetamol to Dexmedetomidine in Pain Management After Adult Cardiac Surgery. Anesth Pain Med. 2021;11(3). e110274. doi: 10.5812/aapm.110274. [PubMed: 34540629]. [PubMed Central: PMC8438704].

2. Yousefshahi F, Samadi E, Paknejad O, Bastan Hagh E, Aminzadeh S. Effect of Hypoxemia in the Determination of Short-Term Prognosis of Coronary Artery Bypass Graft Patients: A Prospective Study. Anesth Pain Med. 2019;9(1). e81785. doi: 10.5812/aapm.81785. [PubMed: 30881905]. [PubMed Central: PMC6408866].

3. Salehi Derakhtanjani A, Ansari Jaberi A, Haydari S, Negahban Bonabi T. Comparison the effect of active cyclic breathing technique and routine chest physiotherapy on pain and respiratory parameters after coronary artery graft surgery: A randomized clinical trial. Anesth Pain Med.2019;9(5). e94654. doi:10.5812/aapm.94654. [PubMed: 31903332]. [PubMed Central: PMC6935291].

4. Javaherforooshzadeh F, Bhandori H, Jarirahmadi S, Bakhtiari N. Investigating the Effect of Near Infra-Red Spectroscopy (NIRS) on Early Diagnosis of Cardiac Surgery-Associated Acute Kidney Injury. Anesth Pain Med.2020;10(6). doi: 10.5812/aapm.109863.

5. Mohod V, Ganeriwal V, Bhange J. Comparison of intensive insulin therapy and conventional glucose management in patients undergoing coronary artery bypass grafting. J Anaesthesiol Clin Pharmacol. 2019;35(4):493. doi: 10.4103/joacp.JOACP_61_17. [PubMed: 31920233]. [PubMed Central: PMC6939551].

6. Girish G, Agarwal S, Satsangi DK, Tempe D, Dutta N, Pratap H. Glycemic control in cardiac surgery: rationale and current evidence. Ann Card Anaesth. 2014;17(3). doi: 10.4103/0971-9784.135873. [PubMed: 24994733].

7. Nystrom T, Holzmann MJ, Eliasson B, Kuhl J, Sartipy U. Glycemic Control in Type 1 Diabetes and Long-Term Risk of Cardiovascular Events or Death After Coronary Artery Bypass Grafting. J Am Coll Cardiol. 2015;66(5):535-43. doi: 10.1016/j.jacc.2015.05.054. [PubMed: 26227192].

8. Zheng J, Cheng J, Wang T, Zhang Q, Xiao X. Does HbA1c Level Have Clinical Implications in Diabetic Patients Undergoing Coronary Artery Bypass Grafting? A Systematic Review and Meta-Analysis.
Int J Endocrinol. 2017;2017:1537213. doi: 10.1155/2017/1537213. [PubMed: 29075292]. [PubMed Central: PMC5623764].

9. Robich MP, Iribarne A, Leavitt BJ, Malenka DJ, Quinn RD, Olmstead EM, et al. Intensity of Glycemic Control Affects Long-Term Survival After Coronary Artery Bypass Graft Surgery. Ann Thorac Surg. 2019;107(2):477-84. doi: 10.1016/j.athoracsur.2018.07.078. [PubMed: 30273572].

10. Sedighinejad A, Imantalab V, Mirmansouri A, Mohammadzadeh Jouryabi A, Kanani G, Nassiri Sheikhani N, et al. Effects of Low-dose Selenium on the Inflammatory Response in Coronary Artery Bypass Graft Surgery: A Clinical Trial. Iran Red Crescent Med J. 2016;18(8) e37918. doi: 10.5812/ircmj.37918. [PubMed: 27795837]. [PubMed Central: PMC5070486].

11. Sedighinejad A, Imantalab V, Mirmansouri A, Naderi Nabi B, Tarbiat M, Sadeghi AM, et al. Comparing the Effects of Isoflurane-Sufentanil Anesthesia and Propofol-Sufentanil Anesthesia on Serum Cortisol Levels in Open Heart Surgery with Cardiopulmonary Bypass. Anesth Pain Med. 2016;6(6). doi: 10.5812/aapm.42066.

12. Mirmansouri A, Imantalab V, Mohammadzadeh Jouryabi A, Kanani G Naderi Nabi B, Farzi F, et al. Effect of Selenium on Stress Response in Coronary Artery Bypass Graft Surgery: A Clinical Trial. Anesth Pain Med. 2017;7(1). doi: 10.5812/aapm.43864.

13. Loukas M, Bilinsky S, Bilinsky E, el-Sedfy A, Anderson RH. Cardiac veins: a review of the literature. Clin Anat. 2009;22(1):129-45. doi: 10.1002/ca.20745. [PubMed: 19097063].

14. Bilehjani E, Nader N, Farzin H, Haghighate Azari M, Fakhari S. The Evaluation of Factors Affecting Hemodynamic Variability in Mechanically-Ventilated Patients After Cardiac Surgery. Anesth Pain Med. 2020;10(4). doi: 10.5812/aapm.101832.

15. Rehman I, Rehman A. Anatomy, Thorax, Heart. StatPearls; 2017.

16. Wisneski JA, Gertz EW, Neese RA, Gruenke LD, Morris DL, Craig JC. Metabolic fate of extracted glucose in normal human myocardium. J Clin Invest. 1985;76(5):1819-27. doi: 10.1172/JCI112174. [PubMed 4056055]. [PubMed Central: PMC424216].

17. Gertz EW, Wisneski JA, Neese R, Bristow JD, Searle GL, Hanlon JT Myocardial lactate metabolism: evidence of lactate release during net chemical extraction in man. Circulation. 1981;63(6):1273-9. doi: 10.1161/01.cir.63.6.1273. [PubMed: 6784963].

18. Bergman BC, Tsvetkova T, Lowes B, Wolfel EE. Myocardial glucose and lactate metabolism during rest and atrial pacing in humans. Physiol J. 2009;587(9):2087-99.

19. Sathya B, Davis R, Taveira T, Whitlatch H, Wu WC. Intensity of perioperative glycemic control and postoperative outcomes in patients with diabetes: a meta-analysis. Diabetes Res Clin Pract. 2013;102(1):8-15. doi: 10.1016/j.diabres.2013.05.003. [PubMed: 23746852].

20. Haga KK, McClymont KL, Clarke S, Grounds RS, Ng KY, Glyde DW, et al. The effect of tight glycaemic control, during and after cardiac surgery, on patient mortality and morbidity: A systematic review and metaanalysis. J Cardiothorac Surg. 2011;6(1):1-10. doi: 10.1186/1749-8090-6-3. [PubMed: 21219624]. [PubMed Central: PMC3023693] 